\title{
図学研究 第20号までの正誤表
}

会誌図学研究の創刊10周年を閲し，第 1 号から第 20 号までに掲載された論文，発表要旨，寄 書，随想のすべてにわたって，執筆者から送られた正誤表を掲載することになり，編集宛に原 稿をお送りいた心゙きました。既に編集の手元に届いたものを，以下に号を追って掲載します。

図学研究 第 5 号

光源の移動と陰影

千 葉 睦 朗

\begin{tabular}{c|c|c|c}
\hline 頁 & 行 $($ 上から $)$ & 誤 & 正 \\
\hline 21 & 13 & $\cdots \cdots 36^{\circ} 16^{\prime} \cdots \cdots$ & $\cdots \cdots 35^{\circ} 16^{\prime} \cdots \cdots$ \\
\hline
\end{tabular}

黎明期の困学教育

原正 敏

\begin{tabular}{c|c|c|l}
\hline 頁 & 行 $($ 上から $)$ & \multicolumn{1}{|c}{ 誤 } & \multicolumn{1}{|c}{ 正 } \\
\hline 58 & 6 & 〔1 部〕は & 5 行目の末尾に移す \\
64 & 註 15$)$ & 信濃教育会「赤松小三郎先生」 & $\begin{array}{l}\text { 沼田次郎 前出書 93頁 } \\
\text { 1957を追加 }\end{array}$ \\
\hline 65 & 註 29$)$ & & \\
\hline
\end{tabular}

図学研究 第 6 号

透視投象における軸測尺の研究 小高 司 郎

\begin{tabular}{c|c|c|c}
\hline 頁 & 行 $($ 上から $)$ & 誤 & 正 \\
\hline 11 & 2 & $\sqrt{\mathrm{b}^{2} \mathrm{ab} \cos \gamma-\mathrm{bc} \cos \alpha+\cdots}$ & $\sqrt{\mathrm{b}^{2}-\mathrm{ab} \cos \gamma-\mathrm{bc} \cos \alpha \cdots}$ \\
\hline
\end{tabular}

作困線を引かずに描く軸測困法 フリッツ・ホーエンベルク（増田祥三訳）

\begin{tabular}{c|l|l|l}
\hline 頁 & 行 $($ 上から $)$ & \multicolumn{1}{|c|}{ 誤 } & \multicolumn{1}{|c}{ 正 } \\
\hline 3 & 14 & $\sqrt{1-2 \lambda(1-\lambda)(1-\cos \omega) \cdot \mathrm{e}}$ & $\sqrt{1-2 \lambda(1-\lambda)(1-\cos \omega)} \cdot \mathrm{e}$ \\
6 & 13 & Abzählwng & Abzählung \\
\hline
\end{tabular}

フリッツ・ホーエンベルク教授について 増 田祥 三

\begin{tabular}{c|l|l|l}
\hline 頁 & 行 $($ 上から $)$ & \multicolumn{1}{|c}{ 誤 } & \multicolumn{1}{c}{ 正 } \\
\hline 7 & 2 & 招介 & 紹介 \\
7 & 18 & Penspektiven & Perspektiven \\
7 & 19 & 図学関係をとって & 図学関係者として \\
7 & 30 & 少人類 & 少人数
\end{tabular}




\begin{tabular}{l|l|l|l}
7 & 37 & Werkstatttechnik & Werkstattstechnik \\
8 & 6 & ことにしよj & ことにしましょj \\
8 & 14 & 存職 & 在職 \\
8 & 33 & 畢性 & 畢生 \\
8 & 36 & 訓練によっていj & 訓練によってという \\
\hline
\end{tabular}

図学研究 第 7 号

透視図射影尺の作困に関する研究

增田祥三・竹山和彦

\begin{tabular}{|c|c|c|c|}
\hline 頁 & 行（上から） & 䛊 & 正 \\
\hline 2 & 9 & $a$ と $S$ とで & $a$ と $s$ とで \\
\hline 3 & Fig. 5 & $M_{\Gamma}$ & $M$ \\
\hline 3 & 18 & $M_{\rho}$ & $M$ \\
\hline 4 & 4 & 始点（ 0 ） & 零点（0） \\
\hline 5 & 12 & $\operatorname{tg} \varphi=x /\left(S-a / s^{\prime} \cdot x\right)$ & $\operatorname{tg} \varphi=x /\left(s-a / s^{\prime} \cdot x\right)$ \\
\hline 6 & 5 & 漸近線は $u$ と $v$ べ & 漸近線は $u$ と $v$ で \\
\hline 6 & 5,6（3ヶ所） & $W$ & $w$ \\
\hline 6 & 式 (5) & $h_{0}=S-h$ & $h_{0}=s-h$ \\
\hline 6 & 式 (6) & $y_{\iota}=\frac{\sqrt{s(s-a)}}{a}(\sqrt{s}-\sqrt{s}-a)^{2}=$ & $y_{l}=\frac{\sqrt{s(s-a)}}{a}(\sqrt{s}-\sqrt{s-a})^{2}$ \\
\hline 7 & 2 & a $/ S$ & $\mathrm{a} / \mathrm{s}$ \\
\hline 9 & 17 & 射形的線束 & 射影的線束 \\
\hline 10 & 3 & 射線 1（1） & 射線 1（0) \\
\hline 10 & 5 & $s$ という記号 & $S$ という記号 \\
\hline 10 & 6 & および $s=$ & および $S=$ \\
\hline 10 & $16,17,20,22$ & 線束 $\boldsymbol{s}$ & 線束 $S$ \\
\hline 12 & Fig. 14 & $\begin{array}{l}\text { (Fig. } 14 \text { の縮尺は誤りであるカ } \\
\text { ばならない。) }\end{array}$ & ら困を1.18倍に拡大しなけれ \\
\hline 13 & 5 (参考文献) & W. Meryer & W. Meyer \\
\hline 14 & 7 & 導双典線 & 導双曲線 \\
\hline
\end{tabular}

図学研究 第 8 号

明治初期の図学教育（II）一工部大学校を中心に一

\begin{tabular}{c|c|c|c}
\hline 頁 & 行 $($ 上から $)$ & 誤 & 正 \\
\hline 35 & 16 & 曾 鿅 達 三 & 曾 襧 達 蔵 \\
\hline
\end{tabular}

図学研究 第 10 号

曲線製図における円の使用について フリッツ・ホーエンベルク（増田祥三訳）

\begin{tabular}{l|l|l|l}
\hline 頁 & 行 (上から $)$ & \multicolumn{1}{c}{ 誤 } & \multicolumn{1}{c}{ 正 } \\
\hline 25 & 式 $(1)$ & $=\int_{0}^{\varepsilon}$ & $=\int_{0}^{\varepsilon}$ \\
26 & 1 & $=\int_{0}^{x} \sqrt{1+y^{\prime 2}} d x$ & $=\int_{0}^{x} \sqrt{1+y^{\prime 2}} d x$ \\
26 & $11(2$ ケ所 $)$ & $=\int_{0}^{\varepsilon}$ & $=\int_{0}^{\varepsilon}$ \\
27 & 10 & $1-\lambda \leqq \kappa_{+} / \kappa \leqq 1+\lambda$ & $1-\lambda \leqq \kappa_{+} / \kappa_{-} \leqq 1+\lambda$ \\
\hline
\end{tabular}




\begin{tabular}{|c|c|c|c|}
\hline 頁 & 行（上から） & 䛊 & 正 \\
\hline 28 & 26 & $\begin{array}{l}\left(y_{1}-y_{2}\right)_{\varepsilon}=\frac{1}{6} k^{\prime} \varepsilon^{3}+\cdots \text { および } \\
\left(y_{1}^{\prime}-y_{2}^{\prime}\right)_{\varepsilon}=\frac{1}{2} k^{\prime} \varepsilon^{2}+\cdots\end{array}$ & $\begin{array}{l}\overline{\left(y_{1}-y_{2}\right)_{\varepsilon}}=\frac{1}{6} k^{\prime} \varepsilon^{3}+\cdots \text { および } \\
\overline{\left(y_{1}^{\prime}-y_{2}^{\prime}\right)_{\varepsilon}}=\frac{1}{2} k^{\prime} \varepsilon^{2}+\cdots\end{array}$ \\
\hline 30 & 12 & $x=0.04$ & $x=0.4$ \\
\hline 32 & 8 & か大きくとり, 他の円弧 & か小さくとり, 他の円弧 \\
\hline
\end{tabular}

困学研究 第 12 号

デカルトの卵形線の二・三の性質 蛭子井 博 考

\begin{tabular}{|c|c|c|c|}
\hline 頁 & 行（上から） & 䛊 & 正 \\
\hline 37 & 2 & $\triangle \mathrm{S}_{2} \mathrm{~PB}$ & $\triangle \mathrm{S}_{1} \mathrm{~PB}$ \\
\hline 38 & 14 & $\mathrm{Y}_{21} \mathrm{Y}_{12}$ & $\mathrm{Y}_{21}^{\prime} \mathrm{Y}_{12}$ \\
\hline 41 & 20 & 円 $\left(\mathrm{S}_{3}:\right.$ & 円 $\left(\mathrm{S}_{3} ;\right.$ \\
\hline 42 & 27 & $\mathrm{~S}_{2} \mathrm{C}_{1}$ & $\mathrm{~S}_{2} \mathrm{C}_{2}$ \\
\hline 44 & 17 & 摘 & 摑 \\
\hline \multirow[t]{2}{*}{47} & 3 & $\mathrm{n}=\mathbf{m}$ & $\mathrm{n}: \mathrm{m}$ \\
\hline & 3 & $\mathrm{~S}_{1}^{\prime} \mathrm{O}_{21}^{\prime}$ & $\mathrm{S}_{1}^{\prime} \mathrm{O}_{21}^{\prime}: \mathrm{O}_{21}^{\prime} \mathrm{S}_{2}^{\prime}=$ \\
\hline \multirow{2}{*}{48} & 14 & $\cos \left(\frac{x}{2}+r\right)$ & $\cos \left(\frac{\pi}{2}+r\right)$ \\
\hline & & $\sin \left(\frac{\pi}{2}+r\right)$ & $\frac{\pi}{\sin \left(\frac{\pi}{2}+r\right)}$ \\
\hline \multirow[t]{3}{*}{49} & 4 & SCHORNER & SCHÖRNER \\
\hline & & LEHRRUCH & LEHRBUCH \\
\hline & 5 & MUNCHEN & MÜNCHEN \\
\hline
\end{tabular}

四学研究 第 14 号

用語委員会報告 ( I )

日本図学会用語委員会

\begin{tabular}{|c|c|c|c|}
\hline 頁 & 行（上から） & 䛊 & 正 \\
\hline 50 & 28 & 沢田診亮 & 沢田詮亮 \\
\hline 50 & 45 & 昭和18年 & 昭和12年 \\
\hline 51 & 12 & （文献…… & （文責…… \\
\hline 53 & 20 & 258 外転サイクロイド & $\begin{array}{l}\text { 削除欠番とする } \\
\text { (200外転サイクロイド13) }\end{array}$ \\
\hline 53 & 下から 4 行目 & 353 午角面 15 & 353 牛角面 15 \\
\hline 53 & 下から 3 行目 & 354 午角 & 354 牛角 2 \\
\hline 54 & 下から 4 行目 & 520 グラモン投影 & 520 グノモン投影 \\
\hline 57 & 9 & 905 斜螺旋面 & $\begin{array}{l}\text { 削除欠番とする } \\
(772 \text { 斜螺旋面 } 5)\end{array}$ \\
\hline
\end{tabular}


困学研究 第15号

幾何学の新しい視点

フリッツ・ホーエンベルク（増田祥三訳）

\begin{tabular}{l|l|l|l}
\hline 頁 & 行 $($ 上から $)$ & \multicolumn{1}{|c|}{ 誤 } & \multicolumn{1}{c}{ 正 } \\
\hline 2 & 10 & これほど & どれほど \\
2 & 35 & ラーゲル幾何学 & ラゲール幾何学 \\
\hline
\end{tabular}

困学研究 第15号

透視困射影尺の作図に関する研究（2）

増 田 祥 三

\begin{tabular}{|c|c|c|c|}
\hline 頁 & 行（上から） & 誤 & 正 \\
\hline 6 & 16 & $P$ は & $\bar{P}$ は \\
\hline 7 & 1 & 原点 0 & 零点 0 \\
\hline 7 & 26 & 中心 $O^{*}$ & 中心 $\bar{O}^{*}$ \\
\hline 7 & 式 (5) & $O^{*}$ & $\bar{O}^{*}$ \\
\hline 8 & 図 6 & $O O$ & $O \bar{O}$ \\
\hline 8 & 㘡 6 & 1 （左の方） & $1_{U}$ \\
\hline 8 & 式 (6) & $\left(\frac{d \tan p}{h}\right)$ & $\left(\frac{d \tan \alpha-p}{h}\right)$ \\
\hline 8 & 17 & $M H \bar{F} 3$ & $M H \bar{F} 3$ \\
\hline 8 & 21 & $\{\bar{U} ; x, y\}$ & $\{\bar{U} ; \bar{x}, \bar{y}\}$ \\
\hline 8 & 式 (8) & $\begin{array}{l}b=\frac{d e}{2\left(d^{2}-e^{2}\right)}\{\sqrt{ } \\
\sqrt{ }\end{array}$ & $\begin{array}{l}b=\frac{d e}{2\left(d^{2}-e^{2}\right)}\{ \\
\sqrt{ }\}\end{array}$ \\
\hline 8 & 26 & 軸作用 & 軸作困 \\
\hline 9 & 9 & $t^{c}$ & $\bar{t}_{c}$ \\
\hline 9 & 15 & 原点 0 & 零点 0 \\
\hline 10 & 18 & & $e_{R}$ \\
\hline 10 & 37 & $\frac{e_{R}^{2}}{d-e_{R}^{2}}$ & $\frac{e_{R}^{2}}{d^{2}-e_{R}^{2}}$ \\
\hline 11 & 図 9 & $y \bar{y} \quad （$ 下の方） & $y_{R} \bar{y}_{R}$ \\
\hline 11 & 困 9 & $3_{R}$ & 3 \\
\hline 11 & 式 (16) & $(d \tan \alpha-p)^{2}$ & $(d \tan \alpha-\lambda p)^{2}$ \\
\hline 11 & 式 (16) & $\bar{a}=$ & $\bar{\alpha}=$ \\
\hline 11 & 式 (17) & $(d \tan \alpha-p)^{2}$ & $(d \tan \alpha-\lambda p)^{2}$ \\
\hline 11 & 24 & $\bar{O}_{\mathrm{I}}$ & $O_{\mathrm{I}}$ \\
\hline 11 & 26 & 像 $a_{\mathrm{I}}$ & 像 $\bar{a}_{1}$ \\
\hline 11 & 29 & $O_{\mathrm{II}}=O_{\mathrm{II}}$ & $\bar{O}_{I I}=O_{I I}$ \\
\hline 11 & 32 & $d+g=$ & $d+q=$ \\
\hline 11 & 33 & $\bar{e}=\lambda e_{1}$ & $\bar{e}=\lambda \bar{e}_{1}$ \\
\hline 12 & 困 10 & $F_{1} \quad （$ 右破線の上） & $\bar{F}_{\mathrm{I}}$ \\
\hline 12 & 式 (18) & $h \frac{g(d+q)-e^{2}}{(d+q)^{2}-e^{2}}$ & $h \frac{q(d+q)-e^{2}}{(d+q)^{2}-e^{2}}$ \\
\hline
\end{tabular}




\begin{tabular}{|c|c|c|c|}
\hline 頁 & 行（上から） & 䛊 & 正 \\
\hline 12 & 式 (18) & $\begin{array}{r}\sqrt{\left.p^{2}+\sqrt{(d+q)^{2}-e^{2}}+h\right\}^{2}} \\
(\text { 前項) }\end{array}$ & $\sqrt{p^{2}+\left\{\sqrt{(d+q)^{2}-e^{2}}+h\right\}^{2}}$ \\
\hline 12 & 式 (18) & $\begin{array}{l}\sqrt{p^{2}+\left\{\sqrt{(d+p)^{2}-e^{2}}+h\right\}^{2}} \\
-\sqrt{p+\left\{\sqrt{d+q)^{2}-e^{2}}-h\right\}^{2}}\end{array}$ & $\begin{array}{l}\sqrt{p^{2}+\left\{\sqrt{(d+q)^{2}-e^{2}}+h\right\}^{2}} \\
-\sqrt{p^{2}+\left\{\sqrt{(d+q)^{2}-e^{2}}-h\right\}^{2}}\end{array}$ \\
\hline 13 & 1 & 5. 総 括 & 4. 総 括 \\
\hline 13 & 10 & $R_{y} t_{z}$ & Rytz \\
\hline 13 & 18 & $g \in O_{\mathrm{I}}$ & $g \ni O_{\mathrm{I}}$ \\
\hline 13 & 18 & $=d+g$ & $=d+q$ \\
\hline
\end{tabular}

図学研究 第15号

用語委員会報告（II）

日本困学会用語委員会

\begin{tabular}{|c|c|c|c|}
\hline 頁 & 行（上から） & 䛊 & 正 \\
\hline 23 & 下から 2 行目 & 1139正六角錐 & 1139正六角錐 2 \\
\hline 24 & 8 & 1204 錐近錐面 2 & 1204 漸近錐面 2 \\
\hline 26 & 24 & 1613直断面 & 削除欠番とする（1505直断面 4) \\
\hline 26 & 下から 5 行目 & 1659 点跡線 13 & 1659 転跡線 13 \\
\hline 27 & 2 & 1667定傾トセル & 1667定傾トルセ \\
\hline 27 & 28 & 1772等測面 & 削除欠番とする \\
\hline 29 & 2 & 1955歯 & 削除欠番とする（1951歯(2)） \\
\hline 29 & 13 & 1989左側画図 2 & 1989左側面図 2 \\
\hline 30 & 下から 1 行目 & 2265 補助投影線 & 削除欠番とする \\
\hline
\end{tabular}

図学研究 第16号

幾何学の応用

フリッッ・ホーエンベルク（増田祥三訳）

\begin{tabular}{c|r|r|r}
\hline 頁 & 行 $($ 上から $)$ & 誤 & 正 \\
\hline 17 & 3 (脚注 $\left.^{* *}\right)$ & Prof. Dr. Frity & Prof. Dr. Fritz \\
\hline
\end{tabular}

困学研究 第17号

近似展開のパラドックス

小高 司 郎

\begin{tabular}{c|c|r|r}
\hline 頁 & 行 $($ 上から $)$ & 誤 & 正 \\
\hline 39 & 23 & $=2 \pi \mathrm{r}^{2} \times 1.724 \cdots$ & $=2 \pi \mathrm{r}^{2} \times 1.714 \cdots$ \\
\hline
\end{tabular}


図学研究 第18号

線織面近似展開の微分幾何学的研究 (1)

小 高 司 郎

\begin{tabular}{|c|c|c|c|}
\hline 頁 & 行（上から） & 䛊 & 正 \\
\hline 4 & 10 & $\sqrt{\cdots \cdots \cdots \cdots \cdots \cdots\}^{2} d x d y}$ & $\sqrt{\cdots \cdots \cdots \cdots \cdots \cdots\}^{2}} d x d y$ \\
\hline 6 & 7 & $\frac{\cdots+\log \left(G_{1}+\sqrt{ }\right.}{\cdots-G_{1} \sqrt{1+G_{1}^{2}}+\log \left(G_{2}\right.}$ & $\begin{array}{l}\frac{-\log \cdots}{\overline{G_{2}^{2}}-\log \cdots} \mid \\
\cdots+\log \left(G_{1}+\sqrt{1+G_{1}^{2}}\right)-\log \cdots \\
1+G_{1}^{2}+\log \left(G_{2}+\sqrt{1+G_{2}^{2}}\right)-\log \cdots\end{array}$ \\
\hline 6 & 19 & {$\left[\left(\frac{\partial^{2} \lambda}{\partial G_{1}^{2}}-\frac{\partial^{2} \lambda}{\partial G_{2}^{2}}\right)-(\cdots \cdots\right.$} & {$\left[\left(\frac{\partial^{2} \lambda}{\partial G^{2}} \cdot \frac{\partial^{2} \lambda}{\partial G_{2}^{2}}\right)-(\cdots\right.$} \\
\hline 6 & 25 & $\lambda=\frac{(1+\mathbf{k})^{2}}{1+\mathrm{k}^{2}}$ & $\lambda=\frac{(1-k)^{2}}{1+k^{2}}$ \\
\hline
\end{tabular}

透視図射影尺の作図に関する研究（3）

増 田祥 三

\begin{tabular}{|c|c|c|c|}
\hline 頁 & 行 (上から) & 䛊 & 正 \\
\hline 9 & 図 1 （右図） & $P_{x o}, P_{x o}^{\prime}, P_{y o}, P_{y o}^{\prime}$ & $P_{x}, P_{x}^{\prime}, P_{y}, P_{y}^{\prime}$ \\
\hline 12 & 6 & $=\mathbf{c} \times \overline{\mathbf{f}}$ & $=c_{R} \bar{f}$ \\
\hline 14 & 4 & $a_{1}$ & $\overline{\mathbf{a}}_{1}$ \\
\hline 14 & 5 & $\mathbf{a}_{2}$ & $\overline{\mathbf{a}}_{2}$ \\
\hline 14 & 5 & $\mathbf{a}_{1}$ & $\overline{\mathbf{a}}_{1}$ \\
\hline 14 & 12 & 交会射線が & 交会射線や \\
\hline 14 & 16 & $\overline{\mathrm{E}}_{3}$ & $\overline{\mathrm{E}}_{31}$ \\
\hline 14 & 21 & $\overline{\mathbf{a}}_{2}$ & $\overline{\mathbf{a}} \dot{z}$ \\
\hline 15 & 25 & 下に二消点透視困 & 下の二消点透視困 \\
\hline 15 & 9（参考文献） & Geo & Geo- \\
\hline 10 & $18(2), 19(2))$ & & \\
\hline 11 & $20,21,38$ & ヒあろいはコ & に市乃山は \\
\hline 13 & $19(2)$ & Cक केष्रु & (क) को. 25 \\
\hline 15 & $3(2), 5,6,18)$ & & \\
\hline & (2)は 2 ヶ所 & & \\
\hline
\end{tabular}

グラーツ工業大学幾何学教室について ハンス・フォグラー（増田祥三訳）

\begin{tabular}{|c|c|c|c|}
\hline 頁 & 行（上から） & 誤 & 正 \\
\hline 32 & 8（左段） & 保健数学 & 保険数学 \\
\hline 32 & 12 & ヨーゼス・クラーメス & ヨーゼフ・クラーメス \\
\hline
\end{tabular}


図学研究 第19号

線織面近似展開の微分幾何学的研究 (2)

小高 司 郎

\begin{tabular}{c|l|l|l}
\hline 頁 & 行 $($ 上から $)$ & 誤 & \multicolumn{1}{c}{ 正 } \\
\hline 1 & 欄外 & 神戸大学教養学部 & 神戸大学教養部 \\
\hline
\end{tabular}

デカルトの卵形線の曲率円

蛭子井 博 孝

\begin{tabular}{c|l|l|l}
\hline 頁 & 行 $($ 上から $)$ & \multicolumn{1}{|c}{ 䛊 } & \multicolumn{1}{c}{ 正 } \\
\hline 7 & 21 & $\frac{\mathrm{kc}}{\mathrm{m}-\mathrm{c}}$ & $\frac{\mathrm{kc}}{\mathrm{m}-\mathrm{n}}$ \\
10 & 1 & $\overline{\mathrm{R}}_{1} \overline{\mathrm{R}}_{3}$ & $\overline{\mathrm{R}}_{1} \overline{\mathrm{R}}_{3}^{\prime}$ \\
10 & 33 & $-\frac{\sqrt{\mathrm{k}^{4}-\mathrm{k}^{2} \mathrm{~m}^{2}} \mathrm{c}}{\mathrm{m}^{2}-\mathrm{n}}$ & $-\frac{\sqrt{\mathrm{k}^{2}-\mathrm{k}^{2} \mathrm{~m}^{2}} \mathrm{c}}{\mathrm{m}^{2}-\mathrm{n}^{2}}$ \\
11 & 行外 & 51 年 3 月 & 51 年 9 月 \\
\hline
\end{tabular}

図学研究 第 20 号

\begin{tabular}{c|l|l|l}
\hline 頁 & 行 (上から & \multicolumn{1}{|c}{ 誤 } & \multicolumn{1}{c}{ 正 } \\
\hline 裏表紙 & 16 & Mutsuo CHIBA & Mutsuro CHIBA \\
& 18 & Grophics & Graphics \\
& 25 & Mutsuo CHIBA & Mutsuro CHIBA \\
\hline
\end{tabular}

自動作画方式による立体図の作成

千葉 睦 朗

\begin{tabular}{|c|c|c|c|}
\hline 頁 & 行 (上から) & 誤 & 正 \\
\hline 22 & 四 & 図11 & 図12 \\
\hline 22 & 図 & 図12 & 四11 \\
\hline
\end{tabular}

Projectionの邦訳について

千 葉 睦 朗

\begin{tabular}{|c|c|c|c|}
\hline 頁 & 行（上から） & 䛊 & 正 \\
\hline 41 & 左 24 & 指適し, & 指摘し, \\
\hline 41 & 右 26 & ……まったく用じ…... & ……まったく同じ…… \\
\hline 42 & 右 & 参考文献中 & $\begin{array}{c}4 \text { 4) 根津千治・斉川吾朗 } \\
\text { 用器画の講義と其原理 } \\
\text { (大正15年文理書院 }\end{array}$ \\
\hline 44 & 左 23 & これを用語…... & これ用語….... \\
\hline
\end{tabular}


図学研究 第20号

グラフによる任意の角の奇数等分法と奇数の正多角形の画き方

安部重 義

\begin{tabular}{c|c|c|c}
\hline 頁 & 行 $($ 上から $)$ & 誤 & 正 \\
\hline 28 と29 & & 第 2図と第 4図の入れかえ & 第 4四と第2図の入れかえ \\
\hline
\end{tabular}

